\title{
A comparative study on 10 and 30-year simulation of CMIP5 decadal hindcast precipitation at catchment level
}

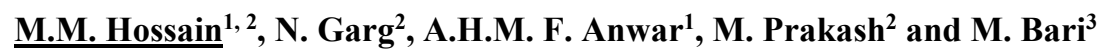 \\ ${ }^{1}$ School of Civil and Mechanical Engineering, Curtin University, GPO Box U1987, Perth, WA 6845, \\ Australia \\ ${ }^{2}$ Commonwealth Scientific and Industrial Research Organisation (CSIRO), Data61, Clayton Vic 3168, \\ Australia \\ ${ }^{3}$ Bureau of Meteorology, West Perth, WA 6872, Australia
}

\begin{abstract}
Early prediction of precipitation has many positive benefits as it enables longer time for proper planning and decision making especially for the water managers, agricultural stakeholders, and policy and decision-makers. However, due to ongoing climate change along with the chaotic nature of precipitation, a too early prediction may lead to inefficient planning and decision making due to higher uncertainty and poor skills of the predicted data as the climate models are imperfect replicas that needs continuous improvement to predict future change. To investigate the difference between the short (a decade) and nearterm (30 years) time simulation, this study aimed to compare the performance of 10 and 30-year simulation of CMIP5 decadal hindcast data of 0.05 degree spatial resolution at catchment level. For this, monthly hindcast precipitation of five general circulation models (GCMs); MIROC4h, MRI-CGCM3, MPI-ESMLR, MIROC5 and CMCC-CM were downloaded from the CMIP5 data portal. Firstly the model data were cut for the Australian region and then the unit of the GCMs data was converted to the millimetre. In the next step, the GCMs data were spatially interpolated onto 0.05 -degree spatial resolution using the secondorder conservative method by Climate Data Operator (CDO) tool. Monthly observed gridded data of 0.05 degree spatial resolution were collected from the Australian Bureau of Meteorology (BoM). In the last step, both the observed and GCMs data were cut for the Brisbane River catchment in Queensland, Australia. Models' performances are assessed comparing with the corresponding observed values through four skill tests; mean bias, mean absolute error, anomaly correlation coefficient and index of agreement. The results show that, 30-year simulations have comparatively higher mean bias and lower skills than 10-year simulated data that seems relevant to ensemble numbers and the external forcing from increasing GHGs due longer simulation period.
\end{abstract}

Keywords: Comparative, decadal, hindcast, precipitation, catchment 
Hossain et al., A comparative study on 10 and 30-year simulation of CMIP5 decadal hindcast precipitation at catchment level

\section{INTRODUCTION}

The Coupled Model Intercomparison Project phase 5 (CMIP5) includes two types of modelling experiments; (i) long-term, which were usually designed for century timescales and (ii) near-term, which were usually designed for 10-30 years' timescale called as decadal experiments (Meehl et al., 2009). In the near-term, there are two core sets of experiments; (i) 10-year hindcasts or predictions initialized in 1960, 1965, 1970 and thus every 5 years to 2005, (ii) 30-year simulation initialized in 1960, 1980 and 2005 and ending simulation by an additional 20 year (Taylor et al., 2012). Both the 10 and 30-year hindcasts prediction were initialized from the similar observed climate states for a particular initialization year but predicted for different time span (10 or 30). However based on the number of ensembles, multiple run of a model with slightly different initialization conditions, the initialization conditions may be slightly different. In addition to the slightly different initialization condition due to different number of ensembles, the external forcing from increasing GHGs may dominate more the model response for 30-year simulation compared to 10-year (Taylor et al., 2012).

Due to the potential applications in many dimensions, decadal experiments have been paid much attentions in the past decade in which temperature and temperature-based climate indices have been paid more attention compared to precipitation. However, precipitation is an important climate variable and hydrological aspect which has been significantly affected around the globe due to ongoing climate change. High temporal and spatial variability along with chaotic nature made difficult for the climate models to project the change in the future precipitation than temperature (Zeke Hausfather, 2018). Climate change is an ongoing dynamic process that is being continuously changed and will also continue in the future. However, the rate of change of future climate and its potential impact on precipitation is not certain. According to the IPCC report (IPCC, 2014), the change in the precipitation amount and its extreme events (e.g., heavy rainfall, droughts) will be higher in the future compared to the past depending on the geographical locations. As every year the climate condition is being changed, that would be intensified in the future, models' projected precipitation for longer timescale may become with higher uncertainty compared to shorter timescale predictions. However, there are always some agreements and disagreements among the models as they are imperfect replicas but they are continuously improving to project the change in future precipitation (Zeke Hausfather, 2018).

Information of local climate features, especially precipitation, are very important for local water managers, developers of water supply infrastructures, and water-related other stakeholders. That is why research on the local level's climate variables and their potential applications are high in demand for transferring research-based scientific knowledge to increase the resilience of the society to climate change (Kumar et al., 2013). Since climate change and its impact on precipitation varies from region to region, therefore, it is important to assess the models' predicted precipitation for every individual region and for finer spatial resolutions for the regions where the most variable climate exists, like in Australia. Few studies (Gaetani and Mohino, 2013; Lovino et al., 2018; Mehrotra et al., 2014) are carried out to assess the CMIP5 decadal precipitation around the globe but no study was at the catchment level and finer than 0.5-degree spatial resolution. Early prediction of precipitation allows longer time to proper planning and decision-making process for managing water resources, assessing future water availability, agricultural planning and large scale investment for infrastructure development (Hansen et al., 2011; Jones et al., 2000; Mehta et al., 2013). But too early may lead to inefficient planning and decision making due to higher uncertainty in the models predicted longer timescale precipitation data. The reason behind is, the chaotic nature of precipitation over time and space as well as the climate models are not perfect enough. To examine that, this study aimed to compare the performance of 10 and 30 years simulated precipitation for CMIP5 decadal hindcast precipitation at a catchment level of 0.05 -degree spatial resolution.

\section{Data collection and processing}

Monthly observed rainfall of $5 \mathrm{~km} \times 5 \mathrm{~km}$ gridded data, produced through the Water Resources Assessment Landscape model (AWRA-L V5), was collected from the Australian Bureau of Meteorology (BoM). A detail description of the observed data is available here (Frost et al., 2016).

Monthly hindcast precipitation data from five GCMs (Table 1), who have both the 30 and 10 years simulations, are collected from the CMIP5 data portal (https:/esgf-node.llnl.gov/projects/cmip5/). There are three initialization years; 1960 (1961-1990), 1980 (1981-2010), and 2005 (2006-2035) which have 30year simulations. However, in this study, the initialization year 1960 and 1980 for 30-year simulation were selected as the observed data available until 2020 only. For better comparison, 30-year datasets were divided into three equal decades thus matching with the time span of 10-year simulation data initialized in 1960, 70, 80, 90 and 2000. Firstly, all available ensembles were averaged to produce a single dataset for each initialization and then the averaged dataset were subset for the Australian region. Secondly, the 
Hossain et al., A comparative study on 10 and 30-year simulation of CMIP5 decadal hindcast precipitation at catchment level

precipitation unit was converted to the millimetre and the datasets were spatially interpolated onto $0.05^{\circ} \times$ $0.05^{\circ}(5 \mathrm{~km} \times 5 \mathrm{~km})$ grids matching with the grids of observed data. The second-order conservative (SOC) method was employed through Climate Data Operator (CDO) tool as SOC was found comparatively better than other commonly used spatial interpolation methods (Hossain et al., 2021a). Finally both the observed and GCMs' data of $5 \mathrm{~km} \times 5 \mathrm{~km}$ spatial resolution were cut for Brisbane River catchment, Queensland, Australia.

Table 1. Model used in this study

\begin{tabular}{|c|c|c|c|c|c|c|c|c|c|}
\hline \multirow{2}{*}{ Models } & \multirow{7}{*}{$\begin{array}{c}\text { Resolutions } \\
\left.\left({ }^{\circ} \text { lon } \times{ }^{\circ} \text { lat }\right)\right)\end{array}$} & \multicolumn{7}{|c|}{10 year simulation. } & \multicolumn{3}{c|}{$\begin{array}{c}30 \text { year } \\
\text { simulation. }\end{array}$} \\
\cline { 3 - 10 } & & $\begin{array}{c}1961- \\
70\end{array}$ & $\begin{array}{c}1971- \\
80\end{array}$ & $\begin{array}{c}1981- \\
90\end{array}$ & $\begin{array}{c}1991- \\
00\end{array}$ & $\begin{array}{c}2001- \\
10\end{array}$ & $\begin{array}{c}1961- \\
90\end{array}$ & $\begin{array}{c}1981- \\
10\end{array}$ \\
\cline { 3 - 10 } & & \multicolumn{7}{|c|}{ Number of ensembles } \\
\hline MIROC4h & $(0.5625 \times 0.5616)$ & 03 & 03 & 06 & 06 & 06 & 03 & 04 \\
\hline MRI-CGCM3 & $(1.125 \times 1.1215)$ & 06 & 09 & 06 & 09 & 09 & 03 & 03 \\
\hline MPI-ESM-LR & $(1.875 \times 1.865)$ & 10 & 10 & 10 & 10 & 10 & 03 & 03 \\
\hline MIROC5 & $(1.4062 \times 1.4007)$ & 06 & 06 & 04 & 06 & 06 & 06 & 04 \\
\hline CMCC-CM & $0.75 \times 0.748$ & 03 & 03 & 03 & 03 & 03 & 03 & 03 \\
\hline
\end{tabular}

\section{Study Area}

Brisbane River catchment is in Queensland, the eastern state of Australia. It lies in between the latitudes 26.50S and 28.150S and the longitudes 151.70E and 153.150E. It has an area of 13549 square kilometres and a sub-tropical climate where maximum rainfall occurs during summer (December-January-February) and minimum rainfall in winter (June-July-August) (Climate Data, 2020).

\section{METHODOLOGY}

The comparisons between the 10 and 30-year simulations were performed based on the corresponding observed values through four quantitative performance metrics; Mean Bias, Mean Absolute Error (MAE), Anomaly Correlation Coefficient (ACC) and Index of Agreement (IA) which are usually referred to as skill tests.

(i) Mean Bias: Choudhury et al., (2017) presented the difference between the raw ensembles' mean and the corresponding observed values as mean bias. As this study used mean of all available ensembles, the mean bias can be obtained from the absolute differences between the models' predicted ensembles' mean and the corresponding observed values [henceforth the mean bias will be referred as bias].

$$
\text { Bias }=\left|P_{i}-O_{i}\right|
$$

Where $P$ and $O$ present models' predicted and observed values respectively and the subscript $i$ varies from 1 to $\mathrm{n}$ where $\mathrm{n}$ is the number of months in each dataset. These notations are the same also for the following skills.

(ii) Mean Absolute Errors (MAE): As the name suggests, MAE presents the average magnitude of the differences between modelled and observed values.

$$
M A E=\frac{1}{n} \sum_{i=1}^{n}\left|P_{i}-O_{i}\right|
$$

(iii) Anomaly Correlation Coefficient (ACC): The centred ACC suggested by Wilks, (2011) measures the correspondence between the anomalies of model predicted and observed values. A higher ACC value does not represent the higher accuracy of the predicted data but the anomalies of the predictions.

$$
A C C=\frac{\sum\left\{\left(P_{i}-\bar{O}\right)-\left(\overline{P_{l}-\bar{O}}\right)\right\} *\left\{\left(O_{i}-\bar{O}\right)-\left(\overline{O_{l}-\bar{O}}\right)\right\}}{\sqrt{\sum\left(P_{i}-\bar{O}\right)^{2}} \sqrt{\sum\left(O_{i}-\bar{O}\right)^{2}}}
$$

Here, $\bar{O}$ presents the decadal mean of the observed values and the bar over the anomalies presents the mean of them.

(iv) Index of Agreement (IA): IA suggested by Wilmot (1982), measures the accuracy of models predicted values corresponding to observed values. IA is bounded between 0 and 1 where, the closer the value to 1 , the more efficient the prediction is

$$
I A=1-\frac{\sum_{i=1}^{n}\left(P_{i}-O_{i}\right)^{2}}{\sum_{i=1}^{n}\left(\left|P_{i}-O^{\prime}\right|+\left|O_{i}-O^{\prime}\right|\right)^{2}}
$$

Here $O^{\prime}$ presents the mean of every individual year of the predicted period. 
Hossain et al., A comparative study on 10 and 30-year simulation of CMIP5 decadal hindcast precipitation at catchment level

\section{RESULTS AND DISCUSSION}

In the Brisbane River catchment, there are 496 grids of $5 \mathrm{~km} \times 5 \mathrm{~km}$ spatial resolution. The aforementioned skills tests are performed for every individual grid of all the selected models and initialization years. For simplicity, the results are presented here for a single grid point $(27.50 \mathrm{~S}$ and $153.050 \mathrm{E})$, which is closest to a BoM's operated automated weather station (AWS, located at $27.480 \mathrm{~S}$ and $153.040 \mathrm{E}$ which is in the northern-east of the Wivenhoe).

The bias are calculated for the monthly data and accumulated for yearly for the sake of brevity in presentation. Figure 1 presents the yearly total bias at the selected grid of the MRI-CGCM3 model. It is evident that 30-year simulation data shows comparatively higher bias as opposed to 10 -year simulations and similar results were found for other models also. However, the magnitude of the bias varies over the models, initialization years and simulation periods.
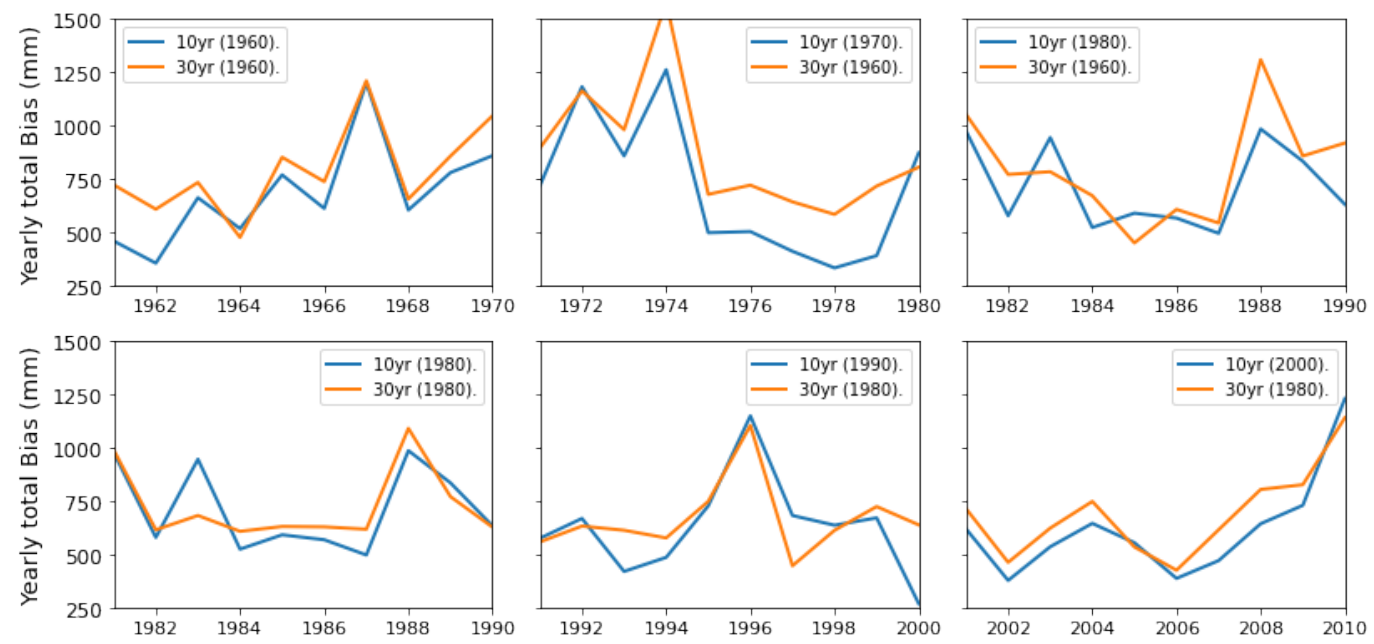

Figure 1. Yearly total bias (obtained from monthly bias) comparisons of 10 and 30 years simulation for MRI-CGCM3 model. The vertical axis presents yearly total of bias and the horizontal axis presents lead time (in year). The initialization years are mentioned in the parenthesis of labels.
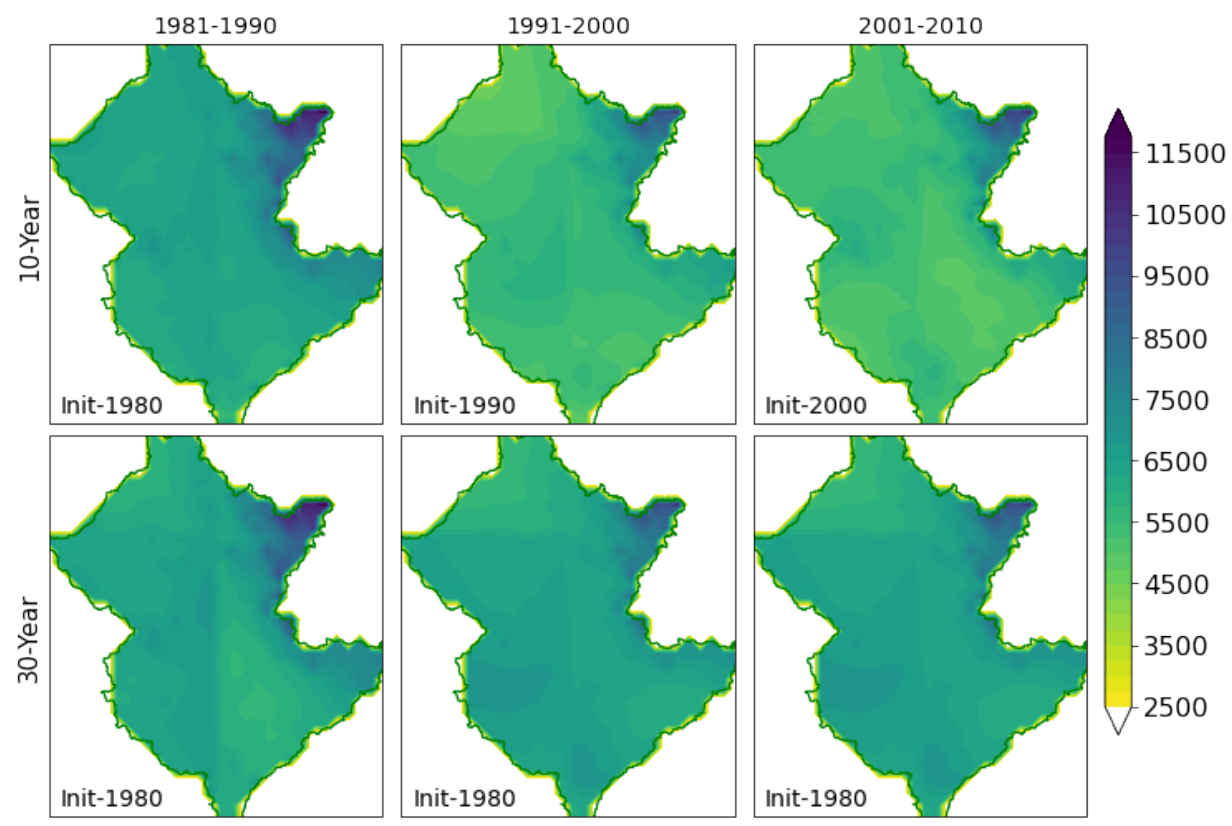

Figure 2. Comparison of total (sum over 120 months) bias between 10 and 30-year simulations across the catchment for the time period of 1981-2010 of MRI-CGCM3 model. The time periods are mentioned on the top of individual columns the initialization years are mentioned at the bottom left corner of individual plots. 
Table 2. Comparison of total bias at the selected grid

\begin{tabular}{|c|c|c|c|c|c|c|c|c|c|c|c|c|}
\hline \multirow{2}{*}{ Models } & \multicolumn{3}{|c|}{10 years simulation } & \multicolumn{3}{|c|}{30 years simulation $(1960)$} & \multicolumn{3}{|c|}{10 years simulation } & \multicolumn{3}{|c|}{30 years simulation $(1980)$} \\
\hline & $1961-70$ & $1971-80$ & $1981-90$ & $1961-70$ & $1971-80$ & $1981-90$ & $1981-90$ & $1991-00$ & $2001-10$ & $1981-90$ & $1991-00$ & $2001-10$ \\
\hline MIROC4h & 7986.7 & 7582.1 & 7387.3 & 7986.7 & 7629.8 & 7935.1 & 7387.3 & 6295.3 & 6840.1 & 8154.6 & 6762.9 & 6649.3 \\
\hline MRI-CGCM3 & 6830.2 & 703 & 712 & 79 & 8 & 7 & 8.3 & 76.4 & 6 & 0.2 & 46.2 & 6886.0 \\
\hline MPI-ESM-LR & 7912.7 & 8356.9 & 7234.4 & 8593.6 & 8827.3 & 8045.1 & 7234.4 & 6930.5 & 7646.4 & 7145.3 & 7470.9 & 7141.8 \\
\hline MIROC5 & 7401.8 & 8250.5 & 7903.1 & 7743.3 & 8811.1 & 8530.2 & 7903.1 & 7716.8 & 7814.2 & 7903.1 & 7407.1 & 8900.8 \\
\hline CMCC-CM & 8150.6 & 9063.1 & 8212.5 & 8150.6 & 9008.2 & 8093.3 & 8212.4 & 6454.2 & 7112.9 & 8212.4 & 6703.6 & 7046.1 \\
\hline
\end{tabular}

Table 3: Comparison of MAE at the selected grid

\begin{tabular}{|c|c|c|c|c|c|c|c|c|c|c|c|c|}
\hline \multirow{2}{*}{ Models } & \multicolumn{3}{|c|}{10 years simulation } & \multicolumn{3}{|c|}{30 years simulation $(1960)$} & \multicolumn{3}{|c|}{10 years simulation } & \multicolumn{3}{|c|}{30 years simulation $(1980)$} \\
\hline & $1961-70$ & $1971-80$ & $1981-90$ & $1961-70$ & 1971-80 & $1981-90$ & $1981-90$ & 1991-00 & $2001-10$ & $1981-90$ & 1991-00 & 2001-10 \\
\hline MIROC4h & 66.55 & 63.18 & 61.56 & 66.55 & 63.58 & 66.12 & 61.56 & 52.46 & 57.0 & 67.95 & 56.36 & 55.41 \\
\hline MRI-CGCM3 & 56.91 & 58.66 & 59.40 & 65.91 & 73.12 & 66.46 & 59.40 & 52.30 & 51.55 & 60.42 & 55.38 & 57.38 \\
\hline MPI-ESM-LR & 65.93 & 69.64 & 60.28 & 71.61 & 73.56 & 67.04 & 60.28 & 57.75 & 63.72 & 59.54 & 62.26 & 59.51 \\
\hline MIROC5 & 61.68 & 68.75 & 65.85 & 64.52 & 73.42 & 71.08 & 65.86 & 64.31 & 65.12 & 65.86 & 61.72 & 74.17 \\
\hline CMCC-CM & 67.92 & 75.52 & 68.43 & 67.92 & 75.06 & 67.44 & 68.43 & 53.78 & 59.27 & 68.43 & 55.86 & 58.72 \\
\hline
\end{tabular}

Table 4: Comparison of ACC at the selected grid

\begin{tabular}{|c|c|c|c|c|c|c|c|c|c|c|c|c|}
\hline \multirow{2}{*}{ Models } & \multicolumn{3}{|c|}{10 years simulation } & \multicolumn{3}{|c|}{30 years simulation $(1960)$} & \multicolumn{3}{|c|}{10 years simulation } & \multicolumn{3}{|c|}{30 years simulation $(1980)$} \\
\hline & $1961-70$ & $1971-80$ & $1981-90$ & 1961-70 & 1971-80 & $1981-90$ & $1981-90$ & 1991-00 & $2001-10$ & $1981-90$ & 1991-00 & $2001-10$ \\
\hline MIROC4h & 0.11 & 0.37 & 0.28 & 0.11 & 0.47 & 0.16 & 0.28 & 0.34 & 0.35 & 0.21 & 0.30 & 0.42 \\
\hline MRI-CGCM3 & 0.30 & 0.43 & 0.26 & 0.22 & 0.10 & 0.24 & 0.26 & 0.27 & 0.28 & 0.23 & 0.22 & 0.22 \\
\hline MPI-ESM-LR & 0.24 & 0.20 & 0.26 & 0.10 & 0.27 & 0.20 & 0.26 & 0.28 & 0.17 & 0.32 & 0.29 & 0.29 \\
\hline MIROC5 & 0.23 & 0.30 & 0.27 & 0.24 & 0.19 & 0.04 & 0.27 & 0.17 & 0.20 & 0.14 & 0.22 & 0.20 \\
\hline CMCC-CM & 0.15 & 0.13 & 0.06 & 0.15 & 0.10 & 0.16 & 0.06 & 0.28 & 0.20 & 0.06 & 0.19 & 0.15 \\
\hline
\end{tabular}

Table 5: Comparison of IA at the selected grid

\begin{tabular}{|c|c|c|c|c|c|c|c|c|c|c|c|c|}
\hline \multirow{2}{*}{ Models } & \multicolumn{3}{|c|}{10 years simulation } & \multicolumn{3}{|c|}{30 years simulation $(1960)$} & \multicolumn{3}{|c|}{10 years simulation } & \multicolumn{3}{|c|}{30 years simulation $(1980)$} \\
\hline & $1961-70$ & $1971-80$ & $1981-90$ & $1961-70$ & $1971-80$ & $1981-90$ & $1981-90$ & 1991-00 & $2001-10$ & $1981-90$ & 1991-00 & $2001-10$ \\
\hline MIROC4h & 0.34 & 0.51 & 0.48 & 0.34 & 0.58 & 0.40 & 0.48 & 0.52 & 0.56 & 0.43 & 0.51 & 0.62 \\
\hline MRI-CGCM3 & 0.41 & 0.44 & 0.45 & 0.41 & 0.24 & 0.42 & 0.44 & 0.40 & 0.39 & 0.39 & 0.39 & 0.38 \\
\hline MPI-ESM-LR & 0.41 & 0.30 & 0.41 & 0.34 & 0.43 & 0.42 & 0.41 & 0.43 & 0.37 & 0.50 & 0.48 & 0.51 \\
\hline MIROC5 & 0.35 & 0.33 & 0.30 & 0.30 & 0.31 & 0.35 & 0.30 & 0.31 & 0.35 & 0.30 & 0.31 & 0.35 \\
\hline CMCC-CM & 0.15 & 0.11 & 0 & 0.15 & 0.06 & 0.25 & 0 & 0.35 & 0.3 & 0 & 0.25 & 0.19 \\
\hline
\end{tabular}


For instance, in 30 years simulation initialized in 1980 [henceforth, referred to as 1980(30)] all models showed comparatively lower bias as opposed to initialized in 1960 [henceforth, referred to as 1960(30)] with few exceptions during 1981-1990. In 10 years simulation, models also showed comparatively lower bias during 1991-2010 as compared to other initialization years. Taylor et al., (2012) mentioned that models may show higher biases at the beginning of the simulation period as compared to the other times. However, in this study for decadal timescale, models showed higher bias in the first decade for 1980(30) and in the second decade for 1960(30) except for MIROC4h, which showed higher bias in the first decade of both 30 years simulations. For 10 years simulations, higher biases were observed after 2-3 years from the starting of the simulation of all selected models. During 1981-1990 all models showed their highest bias in the case of both 30 and 10 years simulations (Table 2) of individual models which was also evident in the skill tests. As individual models, MIROC4h and MRI-CGCM3 showed comparatively lower bias along with higher skills where MRI-CGCM3 is a little ahead of MIROC4h for both the 10 and 30-year simulations except in the last decade of 30 years simulations. On the contrary, CMCC-CM and MIROC5 showed higher bias along with lower skills where CMCC-CM is the little ahead during 1991-2010 and behind during 19711990 than MIROC5. Lower bias along with higher skills of models seems highly relevant to models' atmospheric resolutions where higher resolutions may reason comparatively lower bias and vice-versa that was also reported in previous studies (Jain et al., 2019; Lovino et al., 2018). Though having finer atmospheric resolutions, CMCC-CM showed higher bias and lower skills, it may be due to the different understanding of CMCC-CM for predicting precipitation (Sakamoto et al., 2012) at the local level but may show better performance for different locations and variables (Lovino et al., 2018).

This study also compared the total bias over the entire catchment and found that MRI-CGCM3 showed the lowest total bias during 1981-2010 and 1960-1990 in 10-year case only (Figure 2). For 1960(30), MIROC4h showed a little higher bias than MPI-ESM-LR. In case of longer time simulations (e.g., 30-year), only MIROC5 showing higher bias over the entire catchment during the ending of the predicting periods (not presented) whereas other model showed either the first or in the second decade. CMCC-CM showed the highest bias during the last decade of 1960 (30) only. Other skills; MAE, ACC and IA for the selected grid point are presented in Table 3, 4 and 5 respectively. From the skill tests results, it is revealed that the models skills correspond to the magnitude of bias and MAE. Higher bias resulted in lower skills and vice versa. During 1981-1990, models show the lowest skills and the highest errors whilst higher skills are observed during 1991-2010 which was also reported in previous study (Hossain et al., 2021b). It is assumed that during 1961-1970 and 1981-1990, for both the 30 years and 10 simulations, models had the same initialization conditions except slightly perturbation for different ensembles. However, 30 years simulations showed comparatively higher bias and lower skills compared to corresponding 10 years simulations that may be due to the lower number of ensembles in 30 year simulation as opposed to 10-year. Higher bias in 30-year simulation during 1971-1990 and 1991-2010 due to the different initialization conditions where 10 -year simulation had updated climatic condition for models' initialization compared to the 30 -year. This may indicate that models may not capture the dynamic change of precipitation over the time for longer lead time. In addition, the models were dominated by the external forcing from increasing GHGs that may result in more time-varying bias which is referred as drift (Choudhury et al., 2017; Mehrotra et al., 2014) encountered more in 30-year simulation than the 10 -year. Though a 30 -year time is not long enough in climate studies perspective but compared to a decade it is longer.

\section{CONCLUSION}

This study aimed to compare the performance of 10 and 30-year simulations of CMIP5 decadal hindcast precipitation of 0.05 -degree spatial resolution at catchment level. The skills of two 30-year simulations data were assessed and compared with their corresponding 10-year simulations. However, this study considered only two 30-year simulations; 1960(30) and 1980(30), and did not consider the 30 year simulation which was initialized in 2005 as the observed data until 2035 yet to observe. The performance are compared based on the calculated skills; bias, MAE, ACC and IA. Based on the presented skills at the observed station and total bias over the entire catchment, this study finds comparatively higher bias and lower skills of 30-year simulation compared to 10 -year simulations. Though the differences of bias are not significant but stakeholders may require prudence before taking model based decision and planning. However, this study was limited to only Brisbane River catchment, further investigation for other catchments at other locations are highly encouraged.

\section{ACKNOWLEDGEMENTS}

This study is financially supported by CIPRS and Data61 student scholarship of Curtin University and CSIRO (Commonwealth Scientific and Industrial Research Organisation) respectively which is jointly provided to the first author for pursuing his $\mathrm{PhD}$ study at Curtin University, Australia. Authors are thankful 
Hossain et al., A comparative study on 10 and 30-year simulation of CMIP5 decadal hindcast precipitation at catchment level

to different working groups of CMIP5 for producing and making the model data available. Authors are also thankful to the Australian Bureau of Meteorology for providing their kind support and cooperation.

\section{REFERENCES}

Choudhury, D., Sen Gupta, A., Sharma, A., Mehrotra, R., Sivakumar, B., 2017. An Assessment of Drift Correction Alternatives for CMIP5 Decadal Predictions. Journal of Geophysical Research: Atmospheres 122, 10282-10296.

Climate Data, 2020. Liberia climate: Average Temperature, weather by month, Liberia weather averages.

Frost, A.J., Ramchurn, A., Smith, A., 2016. The Bureau's Operational AWRA Landscape (AWRA-L) Model. Bureau of Meteorology Technical Report.

Gaetani, M., Mohino, E., 2013. Decadal prediction of the sahelian precipitation in CMIP5 simulations. Journal of Climate 26, 7708-7719.

Hansen, J.W., Mason, S.J., Sun, L., Tall, A., 2011. Review of seasonal climate forecasting for agriculture in sub-Saharan Africa. Experimental Agriculture 47, 205-240.

Hossain, M.M., Garg, N., Anwar, A.H.M.F., Prakash, M., 2021a. Comparing Spatial Interpolation Methods for CMIP5 Monthly Precipitation at Catchment Scale. In: Regulwar, D.G., Kahalekar, U.J., Shetkar, R. V., Patil, G.K. (Eds.), Sustainable Water Resources Development and Management. Excel India Publishers, Aurangabad, Maharashtra, India, p. 285.

Hossain, M.M., Garg, N., Anwar, A.H.M.F., Prakash, M., Bari, M., 2021b. Intercomparison of drift correction alternatives for CMIP5 decadal precipitation. International Journal of Climatology joc. 7287.

IPCC, 2014. Climate Change 2014 Synthesis Report. Contribution of Working Groups I, II and III to the Fifth Assessment Report of the Intergovernmental Panel on Climate Change 1-112.

Jain, S., Salunke, P., Mishra, S.K., Sahany, S., 2019. Performance of CMIP5 models in the simulation of Indian summer monsoon. Theoretical and Applied Climatology 137, 1429-1447.

Jones, J.W., Hansen, J.W., Royce, F.S., Messina, C.D., 2000. Potential benefits of climate forecasting to agriculture. Agriculture, Ecosystems and Environment 82, 169-184.

Kumar, S., Merwade, V., Kinter, J.L., Niyogi, D., 2013. Evaluation of temperature and precipitation trends and long-term persistence in CMIP5 twentieth-century climate simulations. Journal of Climate 26, 4168-4185.

Lovino, M.A., Müller, O. V., Berbery, E.H., Müller, G. V., 2018. Evaluation of CMIP5 retrospective simulations of temperature and precipitation in northeastern Argentina. International Journal of Climatology 38, e1158-e1175.

Meehl, G.A., Goddard, L., Murphy, J., Stouffer, R.J., Boer, G.J., Danabasoglu, G., Dixon, K., Giorgetta, M.A., Greene, A.M., Hawkins, E., Hegerl, G., Karoly, D., Keenlyside, N., Kimoto, M., Kirtman, B., Navarra, A., Pulwarty, R., Smith, D., Stammer, D., Stockdale, T., 2009. Can It Be Skillful? Bulletin of the American Meteorological Society 90, 1467-1486.

Mehrotra, R., Sharma, A., Bari, M., Tuteja, N., Amirthanathan, G., 2014. An assessment of CMIP5 multimodel decadal hindcasts over Australia from a hydrological viewpoint. Journal of Hydrology 519, 2932-2951.

Mehta, V.M., Knutson, C.L., Rosenberg, N.J., Olsen, J.R., Wall, N.A., Bernadt, T.K., Hayes, M.J., 2013. Decadal Climate Information Needs of Stakeholders for Decision Support in Water and Agriculture Production Sectors: A Case Study in the Missouri River Basin. Weather, Climate, and Society 5, 27-42.

Sakamoto, T.T., Komuro, Y., Nishimura, T., Ishii, M., Tatebe, H., Shiogama, H., Hasegawa, A., Toyoda, T., Mori, M., Suzuki, T., Imada, Y., Nozawa, T., Takata, K., Mochizuki, T., Ogochi, K., Emori, S., Hasumi, H., Kimoto, M., 2012. MIROC4h-A new high-resolution atmosphere-ocean coupled general circulation model. Journal of the Meteorological Society of Japan 90, 325-359.

Taylor, K.E., Stouffer, R.J., Meehl, G.A., 2012. An Overview of CMIP5 and the Experiment Design. Bulletin of the American Meteorological Society 93, 485-498.

Wilks, D.S., 2011. Statistical Methods in the Atmospheric Sciences, 3rd ed, International Geophysics. Elsevier, $676 \mathrm{pp}$.

Wilmot, C.J., 1982. Some Comments on the Evaluation of Model Performance. Bulletin American Meteorological Society 63, 1309-1313.

Zeke Hausfather, 2018. Explainer: What climate models tell us about future rainfall. Carbon Brief. 